\title{
An Advanced Fracture Characterization and Well Path Navigation System for Effective Re-Development and Enhancement of Ultimate Recovery from the Complex Monterey Reservoir of South Ellwood Field, Offshore California
}

\author{
Quarterly Technical Progress Report \\ Reporting Period Start Date: Jan 1,, 2002 \\ Reporting Period End Date: March 31, 2002 \\ Principal Investigators: Steve Horner (Venoco), Iraj Ershaghi (USC) \\ Issue Date: April 30, 2002 \\ Cooperative Agreement No. DE-FC26-00BC15127
}

Submitting organizations:

Venoco Inc

5464 Carpinteria Ave. Suite J

Carpinteria, CA 93013-1423

University of Southern California

University Park

Los Angeles, CA 90089-1147 


\section{Progress Report January 1, 2002- March 31, 2002}

\section{Disclaimer}

This report was prepared as an account of work sponsored by an agency of the United States Government. Neither the United States Government nor any agency thereof, nor any of their employees, makes any warranty, express or implied, or assumes any legal liability or responsibility for the accuracy, completeness, or usefulness of any information, apparatus, product, or process disclosed, or represents that its use would not infringe privately owned rights. Reference herein to any specific commercial product, process, or service by trade name, trademark, manufacturer, or otherwise does not necessarily constitute or imply its endorsement, recommendation, or favoring by the United States Government or any agency thereof. The views and opinions of authors expressed herein do not necessarily state or reflect those of the United States Government or agency thereof.

\section{Abstract}

Venoco Inc, intends to re-develop the Monterey Formation, a Class III basin reservoir, at South Ellwood Field, Offshore Santa Barbara, California.

Well productivity in this field varies significantly. Cumulative Monterey production for individual wells has ranged from 260 STB to $8,700,000$ STB. Productivity is primarily affected by how well the well path connects with the local fracture system and the degree of aquifer support. Cumulative oil recovery to date is a small percentage of the original oil in place. To embark upon successful redevelopment and to optimize reservoir management, Venoco intends to investigate, map and characterize field fracture patterns and the reservoir conduit system. State of the art borehole imaging technologies including FMI, dipole sonic and cross-well seismic, interference tests and production logs will be employed to characterize fractures and micro faults. These data along with the existing database will be used for construction of a novel geologic model of the fracture network. Development of an innovative fracture network reservoir simulator is proposed to monitor and manage the aquifer's role in pressure maintenance and water production. The new fracture simulation model will be used for both planning optimal paths for new wells and improving ultimate recovery.

In the second phase of this project, the model will be used for the design of a pilot program for downhole water re-injection into the aquifer simultaneously with oil production. Downhole water separation units attached to electric submersible pumps will be used to minimize surface fluid handling thereby improving recoveries per well and field economics while maintaining aquifer support.

In cooperation with the DOE, results of the field studies as well as the new 
models developed and the fracture database will be shared with other operators. Numerous fields producing from the Monterey and analogous fractured reservoirs both onshore and offshore will benefit from the methodologies developed in this project.

This report presents a summary of all technical work conducted during the seventh quarter of Budget Period I.

\section{Table of Contents}

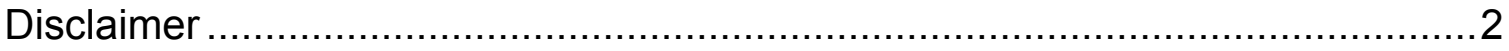

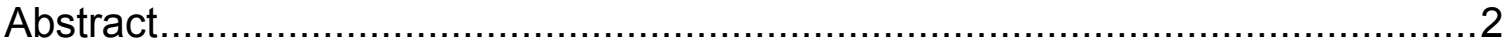

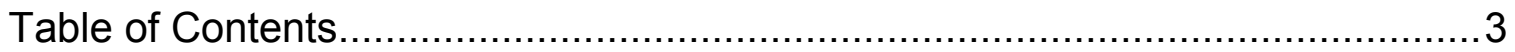

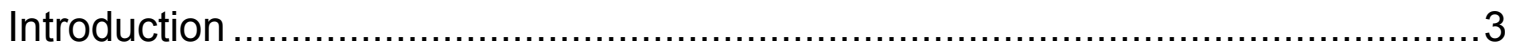

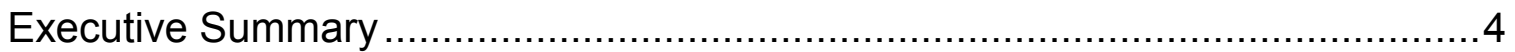

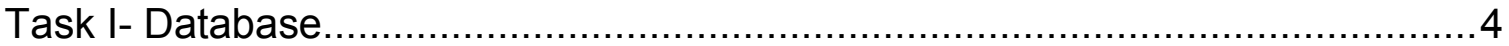

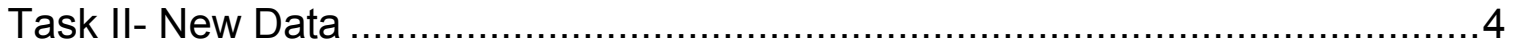

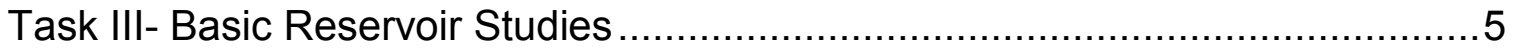

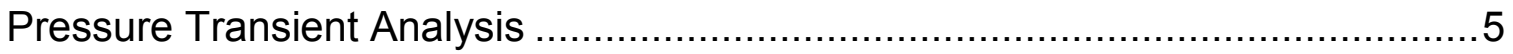

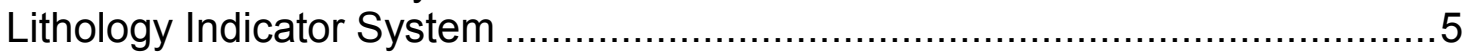

Fluid Entry Surveys and Monitoring of Oil Water Contact ............................. 5

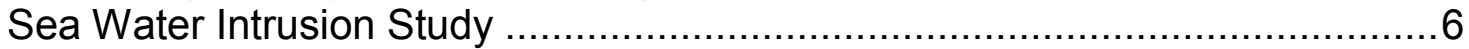

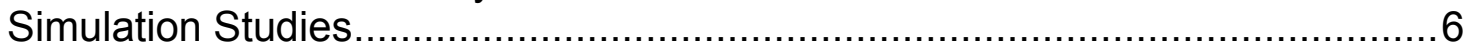

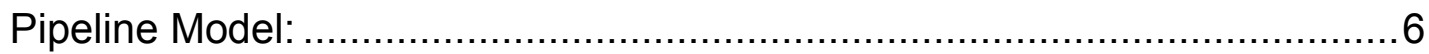

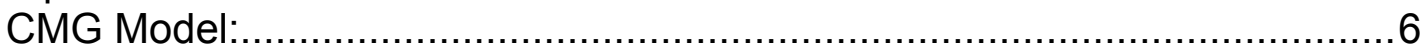

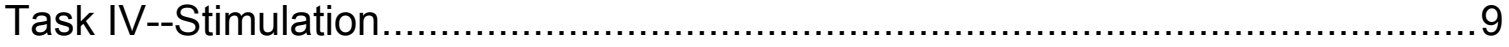

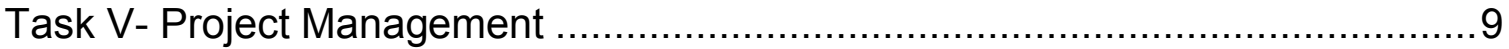

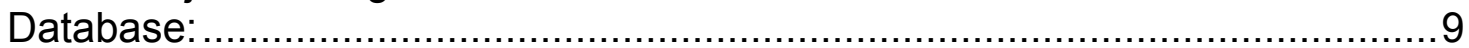

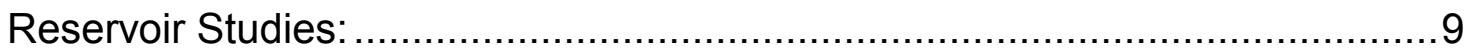

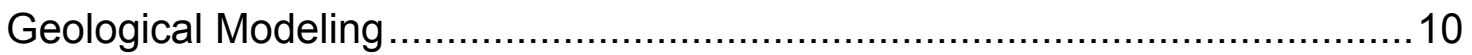

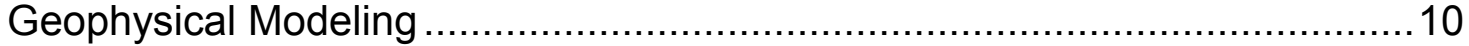

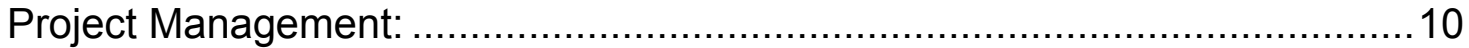

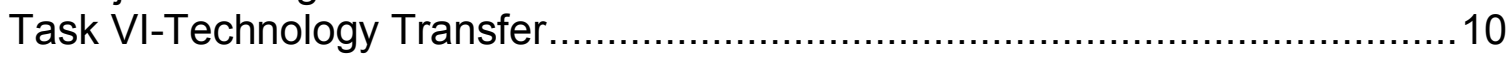

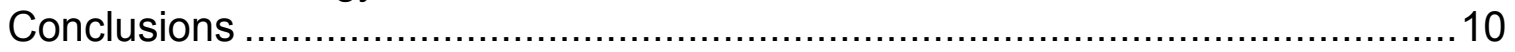

\section{Introduction}

The Field Demonstration site for this Class III (basin clastic) Program Proposal is the South Ellwood Field located offshore California. The Monterey Formation is the main producing unit in the South Ellwood Field and consists of fractured chert, porcelanite, dolomite, and siliceous limestone interbedded with organic mudstone. This reservoir has an average thickness of 1,000 feet, and lies at subsea depths of approximately $-3,500$ ' to $-5,000$ '.

Venoco and USC jointly submitted an application to conduct a DOE co-operative investigation of the Monterey formation at South Ellwood in June 2000. The DOE 
granted this application in July 2000.

\section{Executive Summary}

Venoco and USC prepared a proposal for a DOE sponsored joint investigation of the fractured Monterey formation. It was agreed that Venoco would construct the geologic model for the field and gather new reservoir data as appropriate. USC would then develop a simulation model that would be used to optimize future hydrocarbon recovery. Joint Venoco-USC teams were established to manage the flow of data and insure that Venoco and USC activities remained synchronized. A co-operative agreement was signed with the DOE on July 31, 2000.

This cooperative work between the research team at USC and the operational engineers and geoscientist at Venoco has generated new insight into the evaluation methods for the Monterey Formation and has resulted in the formulation of new approaches to describe reservoir dynamics and to simulate reservoir performance for forecasting purposes. The project has made several contributions to the tech transfer goal of the U.S. Department of Energy. The most prominent of these are; the development of an interactive database on the Monterey Formation, a conceptual model for the description of fracture-controlled Monterey Reservoirs, a pattern recognition method for analysis of well log data and methods for subsurface control of high water production. The first tangible results from this study were obtained this quarter. Successful water shut-off treatments were run in three Holly wells.

\section{$\underline{\text { Task I- Database }}$}

With some delays on transferring the Web Site to the Venoco's server, the work of updating the Interactive Web Based data base continued and we are now preparing the database paper scheduled for presentation at the SPE's Western Regional Meeting in Alaska. We intend to provide a demonstration site for the participants to examine the beneficial aspects of a web based data access system for small to midsize companies.

\section{Task II- New Data}

In November 2000, Schlumberger presented their new PSP/Ghost production logging toolstring. The tool is specifically designed to detect water entry, and differentiate between oil and gas entry in highly deviated wells. We ran the PSP tool in four wells in first quarter 2001. Three of four wells had WSO potential. Water shut-offs have successfully been run on three wells at Platform Holly during the first quarter of 2002. With only one onshore injection well to dispose all of the water produced off of Platform Holly, water disposal is extremely limited at the Ellwood Onshore Facility. The water cut at Platform Holly has risen from $65 \%$ to $75 \%$ in the last three years.

We ran Baker's Thru-Tubing Inflatable Retrievable Bridge Plugs in the three 
wells, 3120-9-1, 3242-12 and 3242-18.

With increasing downtime during this period, is has been difficult to quantify individual well results. Looking at total platform production, and normalizing for excessive downtime, the initial results are an increase of 440 bopd and a 1690 bwpd decrease.

Overall, the WSO program was extremely successful. Based on its success, additional opportunities will be pursued.

\section{$\underline{\text { Task III- Basic Reservoir Studies }}$}

Pressure Transient Analysis

We prepared a pressure survey dataset for the South Ellwood Field:

- We Converted all hardcopy data to digital format (Excel and text files).

- We Initiated a computer aided pressure transient analysis for the wells with available pressure survey data and conducted derivative analysis for pattern recognition.

- Initial results of the analysis shows that the characteristics of fluid flow in South Ellwood Monterey Formation is a complex combination of radial flow, dual porosity behavior, and linear flow in fractures. Work on flow regime identification and reservoir characterization is continuing.

\section{Lithology Indicator System}

The review of log data for the South Ellwood Field is in the final stages of completion. This research resulted in a paper, "A Method for Detection of Untapped Intervals in a Complex Lithology Fractured System" coauthored by USC and Venoco staff. The paper will be presented in Anchorage, AK in May of 2002 at the SPE Western Regional Meeting.

The review of selected 3120 and 3242 wells have identified intervals with production potential based on a lithology pattern recognition system. The system has been applied to the nearby Sockeye Field (also producing from the Monterey Formation) and has yielded similar results. The remaining research work is on two South Ellwood wells where the GHOST Tool was utilized but these wells meet only the minimum required logs signals to implement the pattern recognition system. An alternate review, using Gamma Ray data, is being attempted in an effort to estimate/predict intervals with production potential when one is provided with only minimal well log data for detection of by-passed intervals in the Monterey Formation.

\section{Fluid Entry Surveys and Monitoring of Oil Water Contact}

We continued probing the available fluid entry surveys. Some of the data were found to have been generated from a previous simulation study conducted by a consulting firm. Using the limited actual surveys, we started the development of a 
dataset for front tracking of the oil water contact as a means of assisting the simulation model for history matching of water movement along vertical fractures.

\section{Sea Water Intrusion Study}

We performed a literature survey on sea water intrusion studies in oilfields indicated from chemical analysis of produced water.

- We performed detailed review of produced water chemical composition for a number of South Ellwood wells.

- We generated individual well Stiff diagrams based on gathered water chemical composition data. This technique would reveal if any spatial or temporal variations existed.

- We selected six wells in different areas of the reservoir to obtain more recent chemical analysis data for tracking aquifer invasion.

- Our work is continuing in terms of developing an analytical method for tracking the changes potentially caused by sea water intrusion and the implications with respect to aquifer modeling.

\section{Simulation Studies}

\section{Pipeline Model:}

We started the development of an interface to minimize the substantial time required for pre-processing of data for sensitivity analysis. The interface will be of significant help to other users when the software is released for tech transfer purposes. Meanwhile we continued our formulation of the 2-D three phase flow algorithm and focused on de-bugging of the analytical code.

\section{CMG Model:}

During this quarter, major progress was made in the following aspects of the reservoir simulation.

1. We conducted a number of brain storming sessions to discuss developing the a new dual porosity model and the following conclusions were reached:

- In a single porosity model fracture location is specified through assigning higher permeability and porosity to the specific so-called fracture blocks (compared to other blocks).

- Dual porosity model: The definition of dual porosity model would be primarily based on the structure of single porosity model with matrix blocks showing composite characteristics of a combination of conceptually defined fracture and matrix blocks already implemented in the single porosity model. 


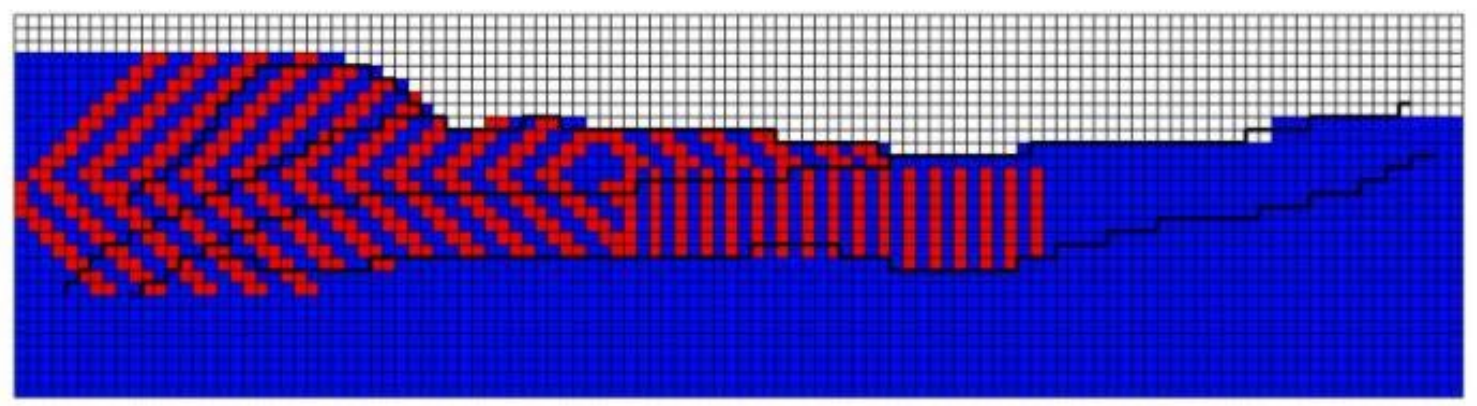

Figure 1: 2D presentation of South Ellwood Monterey Formation simulation model fracture orientation (single porosity model)

Fractures orientation is based on the result of our conventional reservoir engineering studies.

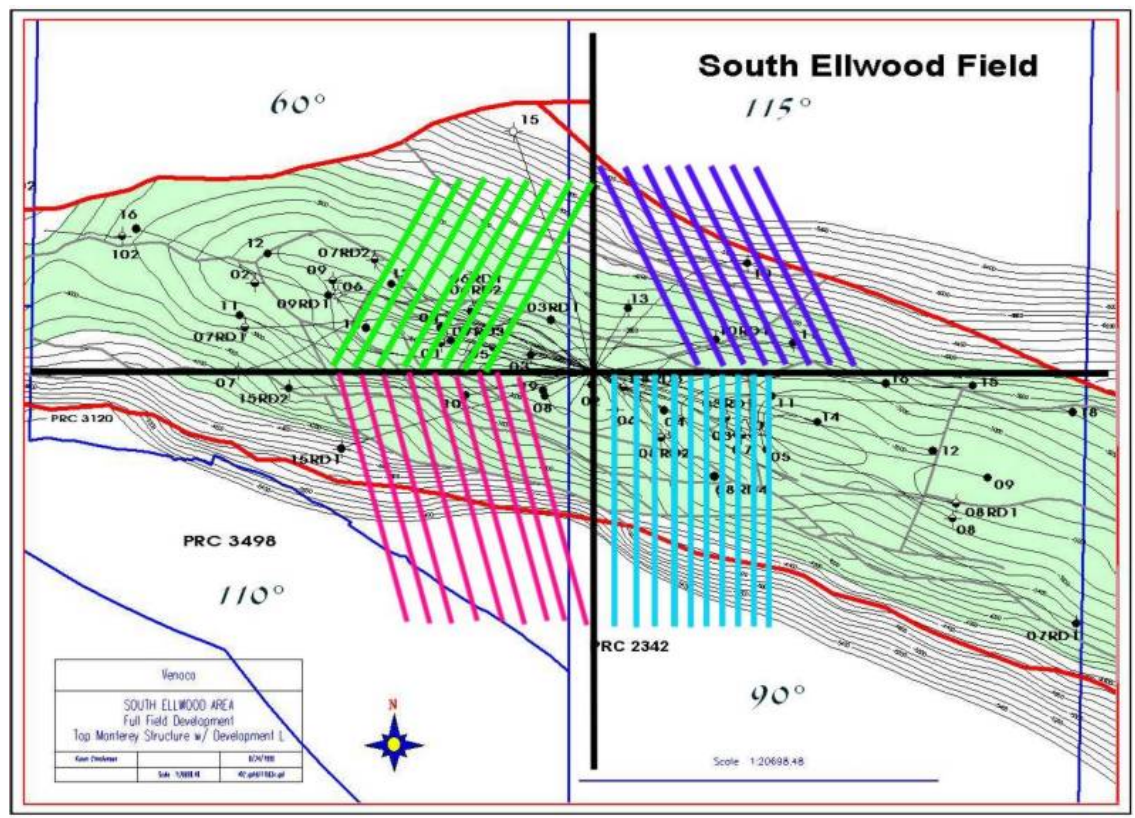

Figure 2: South Ellwood Monterey Formation simulation model fracture orientation (single porosity model) 
2. We reviewed existing perforation data in order to prepare a revised Monterey Formation perforation dataset that would eliminate early production of water from perforations located below the estimated initial water oil contact (WOC). Revised perforation dataset would also incorporate the idea of relocating perforations that presently seem to be located outside the boundaries of current simulation model.

3. We prepared a set of revised production (field-wide, lease-based, and well based) field history files (FHF), incorporating latest production data.

\begin{tabular}{|c|c|c|}
\hline Cumulative Oil, SC & Cumulative Gas, SC & Cumulative Water, SC \\
\hline BBL & MCF & BBL \\
\hline $50,398,767$ & $38,079,353$ & $42,750,988$ \\
\hline
\end{tabular}

\section{Table 1: South Ellwood Monterey Formation Cumulative Production (as of} $05 / 01 / 2000)$

4. We initiated the construction of a tentative dual porosity model in IMEX builder.

5. We incorporated a new gridding strategy into the structure of simulation model in order to have a finer resolution in Z-direction (compared with $\mathrm{X}$ and $Y$ directions).

6. We performed fine-tuning simulation runs to obtain a better understanding of rock-fluid data, component properties, initial conditions, and aquifer properties.

7. We prepared a set of pressure (field-wide, lease-based, and well based) field history files (FHF), incorporating latest field pressure data.

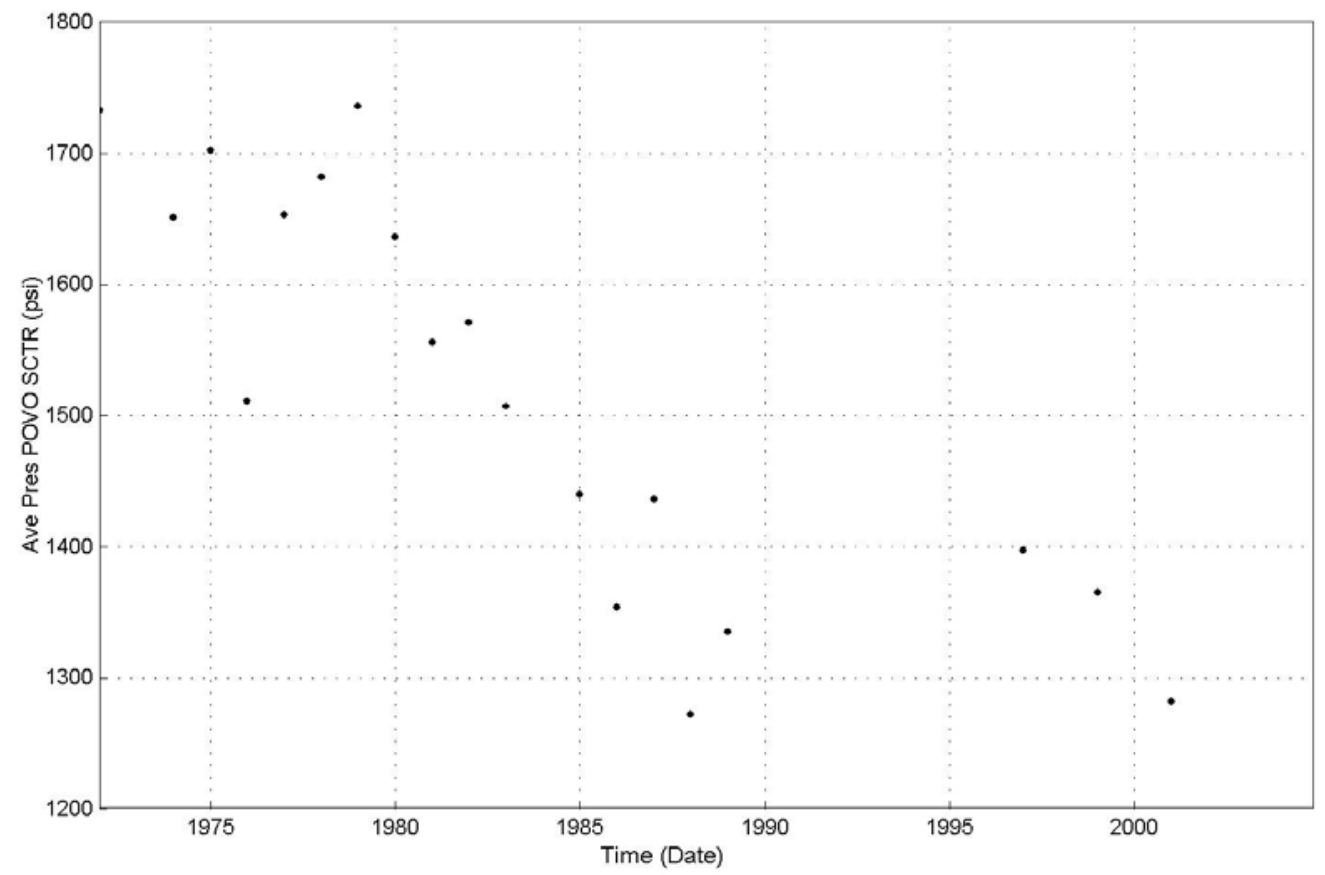

Figure 3: South Ellwood Monterey Formation average reservoir pressure (Original Data) 


\section{$\underline{\text { Task IV--Stimulation }}$}

3120-8 was the discovery well for the Monterey at platform Holly in 1969. The well initially flowed up the annulus at 2100 BOPD. It was an excellent good producer from the Lower Monterey M6 and M7 units until 1978 when an inner string of casing was run to repair casing damage. The well is favorably located in the relatively under-produced central area under the Holly platform. There are no other nearby wells completed in the Lower Monterey.

It was not possible to run the GHOST tool in view of the small diameter tubing size. On the basis of temperature logs and pattern recognition analysis of a limited set of open hole logs, it was decided to shoot 150' of both old and new perforations using 1-11/16" through tubing Pivot guns. The zone was then stimulated by bullheading a high rate mud acid treatment down the tubing in March 2002.

The results were mixed in that the fluid production rate improved but the water cut also increased slightly. The table below gives the before and after well test results for 3120-8.

\begin{tabular}{|rrrrrr|}
\hline Date & BFPD & WC & BOPD & BWPD & GL \\
\hline $3 / 1 / 02$ & 112 & $72 \%$ & 31 & 81 & 230 \\
$3 / 6 / 02$ & 98 & $73 \%$ & 26 & 71 & 228 \\
$3 / 12 / 02$ & 98 & $82 \%$ & 18 & 80 & 232 \\
\hline $3 / 18 / 02$ & 622 & $97 \%$ & 19 & 603 & 250 \\
$3 / 19 / 02$ & 528 & $80 \%$ & 106 & 422 & 278 \\
$3 / 20 / 02$ & 412 & $80 \%$ & 82 & 330 & 274 \\
$3 / 30 / 02$ & 391 & $70 \%$ & 117 & 274 & 209 \\
$4 / 10 / 02$ & 367 & $81 \%$ & 70 & 297 & 257 \\
\hline
\end{tabular}

\section{Task V- Project Management}

Project review meetings were held on a monthly basis in Carpinteria. Progress reports from various individuals were reviewed. Individuals working on the project during this quarter included:

\section{Database:}

I. Ershaghi (USC), H. Patel (USC), Tim Rathmann (Venoco), Katie Boerger (USC), Kim Halbert (Venoco) and Chris Knight (Venoco).

\section{Reservoir Studies:}

I. Ershaghi (USC), Doddy Abdassah (USC), A. Zahedi (USC), Zhengming Yang (USC),), Anthony Taglieri (USC), Steve Horner (Venoco), M. Heidari (USC), M. Kashfi (USC), Raymond Ohusuafr (USC). 


\section{Geological Modeling}

Mike Wracher (Venoco), Karen Christensen (Venoco)

\section{Geophysical Modeling}

Karen Christensen (Venoco)

\section{Project Management:}

Steve Horner (Venoco) and I. Ershaghi (USC)

\section{$\underline{\text { Task VI-Technology Transfer }}$}

We conducted a project review meeting with Mr. Dan Ferguson, the DOE project Manager, and discussed the progress of the project.

Two of the papers accepted for presentation at the SPE Alaska Meeting were prepared and shipped to the SPE office. The Third paper on the database, is under development and will be prepared and delivered at the Alaska Meeting.

\section{Conclusions}

During this reporting period, we saw the first results from our data acquisition campaign. On the basis of the production logs run last year, we were able to conduct three successful water shut-off treatments that both increased oil production and decreased operating costs. In addition, we made major progress in the initiation of pressure history matching for two conceptual models of the reservoir. We documented materials for tech transfer at the upcoming SPE meeting. We started an initiative to calibrate production performance data for imbedded signals that can further assist our simulation studies. Our work on the calibration of well log pattern is approaching the completion phase. 